\title{
Effects of Some Plant Essential Oils against Fungi on Wheat Seeds
}

\author{
Gürsel Karaca*, Melis Bilginturan, Pınar Olgunsoy
}

Plant Protection Department, Faculty of Agriculture, Süleyman Demirel University, 32260 Isparta, TURKEY.

\begin{abstract}
Diseases, especially caused by seed borne fungi, are among the factors decreasing yield and quality of wheat. Common bunt is also an important seed borne disease of wheat worldwide. The objective of the study is to determine the effects of clove, ginger, mint, oregano and thyme oils on the fungal load of wheat seeds. In addition, effects of the oils on the germination rates of bunt spores were investigated. Blotter method was used to determine the effects of different concentrations $(0.05-10 \%)$ of the oils on fungal load of wheat seeds. After incubation at $22^{\circ} \mathrm{C}$ for 7 days, seeds were investigated under stereomicroscope and fungi growing on the seeds were recorded. Germination rates of bunt spores were determined after incubation on water agar with different concentrations of oils. Highest doses of clove, mint and oregano oils totally inhibited the fungal growth on wheat seeds, but they also inhibited the germination of seeds. Lower doses failed to inhibit fungi on seeds, however they decreased or totally inhibited the germination of bunt spores. As a result, it was found that plant essential oils could be used against bunt disease of wheat as an alternative to fungicides.
\end{abstract}

Key words: Triticum aestivum, seed-borne fungi, Tilletia spp., control, Blotter test, Germination rate.

\section{INTRODUCTION}

Wheat (Triticum aestivum L.) is generally acknowledged as the most important agricultural crop since times immemorial. Diseases, especially caused by seed borne fungal agents, are among the main factors reducing yield and quality of wheat. Seed borne pathogens reduce viability, vigor, and germination capability of the seeds resulting in lower yield. Some of them may also cause losses with the diseases on plants growing from the infested seeds. Seed borne fungi not only decrease yield and seed quality, but they also produce mycotoxins which cause diseases on human or animals feeding with these seeds or food made with them. ${ }^{1}$ Seed health is important to obtain higher yields in agriculture. Thus, disease agents on or in the seeds should be determined and controlled. Common bunt is one of the important seed borne diseases of wheat causing significant yield losses and most of the seed lots of winter wheat are treated with synthetic fungicides in order to prevent the disease. ${ }^{2}$ Because of the negative side effects of the fungicides on environment and human health, alternative chemicals or control methods gained importance. Especially in organic agriculture, use of safer chemicals is essential. Plant extracts and essential oils, as safer natural chemicals, ${ }^{3}$ have long been known to have antimicrobial properties and used to control some plant diseases. ${ }^{4,5,6,7}$ There are also some studies on their use against seed borne fungal diseases of some plant species. ${ }^{8,9}$ In the current study, effect of clove, ginger, mint, oregano and thyme essential oils on the fungal load of wheat seeds was determined. In addition, effect of the essential oils on the germination rates of bunt spores was investigated.
DOI: $10.5530 / i j p e r .51 .3 s .53$ Correspondence:

Gürsel Karaca,

Plant Protection Department, Faculty of Agriculture,

Süleyman Demirel University, 32260 Isparta, TURKEY

Phone no: +90 2462114851 Email Id: gurselkaraca@sdu. edu.tr 


\section{MATERIALS AND METHODS}

\section{Determination of the Effects of Oils on Fungal Load and Germination rates of Wheat Seeds}

Wheat seed samples (cv. Alpu-01) and wheat heads infected with bunt disease were obtained from Anadolu Agricultural Research Institute in Eskişehir province. Blotter method was used to determine the effects of different concentrations $(0.01-10 \%)$ of the oils on fungal load of wheat seeds. ${ }^{10}$ Essential oils were applied by two different methods. In the first method, wheat seeds were dipped into oil dilutions for one hour, blotted dry and transferred to blotter papers in petri dishes. In the second method, used in order to determine the volatile effects of the essential oils, $20 \mu$ l oil was applied onto small blotter papers and they were placed on the lids of petri dishes where seeds were transferred. After incubation at $22^{\circ} \mathrm{C}$ for 7 days, seeds were investigated under stereomicroscope and fungi growing on the seeds were recorded. For both methods, seeds not subjected to essential oils served as controls. Means were subjected to analyses of variance after arcsin transformation and were compared by Tukey test.

\section{Determination of the Effects of Oils on Germination Rates of Bunt Spores}

Germination rates of bunt spores were also determined after incubation with different concentrations of oils. Bunt sori were ground and sieved through 4 layers of cheesecloth. Spores were first subjected to surface disinfection with $0.1 \% \mathrm{NaHClO}_{3}$ for 1 min and rinsed two times with sterile distilled water. Then they were suspended in sterile distilled water and $0.5 \mathrm{ml}$ of the suspension was transferred to Petri plates with $3 \%$ water agar after concentration was adjusted to 1000 spores $/ \mathrm{ml}$. Essential oils were applied by two different methods. In the first method, they were incorporated into water agar in 100, 250 and 500 ppm concentrations before pouring into petri dishes. In the second method, undiluted and $10 \%$ diluted oils were applied onto $1 \mathrm{~cm}^{2}$ sterile blotter papers placed on the lids of petri dishes. After incubation at $17^{\circ} \mathrm{C}$ in darkness for 7 days, plates were examined under microscope and spore germination rates were determined. ${ }^{11}$ Petri dishes without essential oils served as controls.

\section{RESULTS \& DISCUSSION}

\section{Effects of Oils on Fungal Load and Germination Rates of Wheat Seeds}

In this study, blotter method which was determined as the best media to isolate the fungi growing on or in the wheat seeds, ${ }^{10,12}$ were used to evaluate the fungal load of the seeds subjected to different doses of the essential oils. Fungal species belonging to Acremonium, Alternaria, Arbrobotrys, Aspergillus, Cladosporium, Epicoccum, Fusarium, Penicillium, Rhizopus, Trichoderma and Ulocladium genera were determined on the wheat seeds. These fungi were previously reported as the most frequent seed borne fungi of wheat. ${ }^{12,13,14,15}$ Effects of the oils on fungal load and germination rates of wheat seeds differed according to the application methods and doses. When the seeds were dipped into oil dilutions, 5 and 10\% doses of the essential oils reduced or totally inhibited fungal growth and germination of the seeds, while lower doses failed to inhibit fungal growth. Clove and oregano oils were the most effective oils and they totally inhibited the fungal growth on the wheat seeds in two higher concentrations, but they also totally inhibit seed germination. Mint oil failed to inhibit seed-borne fungi in 5\% concentration, but this dose significantly lowered the germination rates of the seeds. However, the highest dose of mint oil totally inhibited fungal growth and germination of the wheat seeds (Table 1).

In order to determine the intermediate doses of oregano and mint oils preventing fungal growth but not seed germination, effects of 2, 3 and $4 \%$ doses of clove and oregano oils and 6,7 and $8 \%$ doses of mint oil were investigated. It was found that doses over 3\% of clove oil and $2 \%$ of oregano oil totally inhibited fungal growth on the seeds, while those of mint oil reduced infestation rate to $65 \%$. Unfortunately, intermediate doses of the oils totally inhibited seed germination. Volatile effects of $10 \%$ diluted clove, ginger, mint and thyme essential oils were not sufficient to inhibit the fungi on wheat seeds, while same dose of oregano oil decreased the infestation rate to $70 \%$ and seed germination to $40 \%$. Effects of undiluted oils were better and clove, mint and oregano oils totally inhibit fungal growth, but also decreased or inhibited the germination of wheat seeds (Table 2).

\section{Effects of Essential Oils on Germination Rates of Bunt Spores}

It was determined that ustilospores of Tilletia tritici causing bunt disease on wheat were more sensitive to essential oils used in the study, than other saprobic or parasitic fungi on wheat seeds. All oils totally inhibited the germination of bunt spores when they were added to water agar even in the lowest dose (100 ppm) used in the study. Volatile effects of the undiluted oils were similar and they also inhibited the spore germination. However, 10\% diluted clove and thyme oils were not effective and spore germination rates were similar with control plates. As a result we can recommend soaking 
Table1: Effects of oils on mean fungal infestation and germination rates of wheat seeds dipped in oil dilutions.

\begin{tabular}{|c|c|c|c|}
\hline Doses (\%) & Oils & $\begin{array}{c}\text { Infestation } \\
\text { rate (\%) }\end{array}$ & $\begin{array}{c}\text { Germination } \\
\text { rate }(\%)\end{array}$ \\
\hline \multirow{5}{*}{0.05} & Clove & $100 a^{*}$ & $100 a$ \\
\hline & Ginger & $100 a$ & $100 a$ \\
\hline & Mint & $100 a$ & $100 a$ \\
\hline & Oregano & $100 a$ & $100 a$ \\
\hline & Thyme & $100 a$ & $100 a$ \\
\hline \multirow{5}{*}{1} & Clove & $100 a$ & $100 \mathrm{a}$ \\
\hline & Ginger & $100 a$ & $100 a$ \\
\hline & Mint & $100 a$ & $100 a$ \\
\hline & Oregano & $100 a$ & $100 a$ \\
\hline & Thyme & $100 a$ & $100 a$ \\
\hline \multirow{5}{*}{5} & Clove & $0 \mathrm{~b}$ & $0 d$ \\
\hline & Ginger & $100 a$ & $77,5 \mathrm{~b}$ \\
\hline & Mint & $100 \mathrm{a}$ & $30 \mathrm{c}$ \\
\hline & Oregano & $0 \mathrm{~b}$ & $0 d$ \\
\hline & Thyme & 97,5 a & $30 \mathrm{c}$ \\
\hline \multirow{6}{*}{10} & Clove & $0 \mathrm{c}$ & $0 \mathrm{c}$ \\
\hline & Ginger & $90 \mathrm{ab}$ & $27,5 \mathrm{~b}$ \\
\hline & Mint & $0 \mathrm{c}$ & $0 \mathrm{c}$ \\
\hline & Oregano & $0 \mathrm{c}$ & $0 \mathrm{c}$ \\
\hline & Thyme & $80 \mathrm{~b}$ & $20 \mathrm{bc}$ \\
\hline & Control & $100 a$ & $100 a$ \\
\hline
\end{tabular}

* Means for each dose in the same column shown by the same letter were not statistically different from each other according to Tukey test $(P \leq 0.05)$

\section{Table 2: Volatile effects of oils on fungal infestation} and germination rates of wheat seeds

\begin{tabular}{|c|c|c|c|}
\hline Doses (\%) & Oils & $\begin{array}{c}\text { Infestation } \\
\text { rate (\%) }\end{array}$ & $\begin{array}{c}\text { Germination } \\
\text { rate (\%) }\end{array}$ \\
\hline \multirow{3}{*}{10} & Clove & $100 \mathrm{a}^{*}$ & $100 \mathrm{a}$ \\
\cline { 2 - 4 } & Ginger & $100 \mathrm{a}$ & $100 \mathrm{a}$ \\
\cline { 2 - 4 } & Mint & $100 \mathrm{a}$ & $100 \mathrm{a}$ \\
\cline { 2 - 4 } & Oregano & $70 \mathrm{~b}$ & $40 \mathrm{~b}$ \\
\cline { 2 - 4 } & Thyme & $100 \mathrm{a}$ & $100 \mathrm{a}$ \\
\hline \multirow{7}{*}{100} & Clove & $0 \mathrm{~b}$ & $35 \mathrm{c}$ \\
\cline { 2 - 4 } & Ginger & $100 \mathrm{a}$ & $80 \mathrm{~b}$ \\
\cline { 2 - 4 } & Mint & $0 \mathrm{~b}$ & $0 \mathrm{~d}$ \\
\cline { 2 - 4 } & Oregano & $0 \mathrm{~b}$ & $0 \mathrm{~d}$ \\
\cline { 2 - 4 } & Thyme & $100 \mathrm{a}$ & $25 \mathrm{c}$ \\
\hline & Control & $100 \mathrm{a}$ & $100 \mathrm{a}$ \\
\hline
\end{tabular}

* Means for each dose in the same column shown by the same letter were not statistically different from each other according to Tukey test $(P \leq 0.05)$

infested seeds in plant essential oil suspensions in doses permitting seed germination. There are conflicting results on the effects of some plant juices applied on wheat seeds, against common bunt disease, maybe because of the difference of the application methods, but plants were different from the present study. ${ }^{2-16}$

\section{CONCLUSION}

Highest doses of clove, mint and oregano oils totally inhibited fungal growth and seed germination of wheat seeds. Lower doses permitting seed germination failed to inhibit fungi on seeds, however they decreased or totally inhibited the germination of bunt spores. Plant essential oils can be used against bunt disease of wheat as an alternative to fungicides, especially in the organic production.

\section{ACKNOWLEDGEMENT}

Thanks to Anadolu Agricultural Research Institute for providing the healthy and bunt infested wheat seeds.

\section{CONFLICT OF INTEREST}

None

\section{ABBREVIATION USED}

$\mathrm{cm}^{2}$ : square centimeter; ml: milliliter; $\mu \mathrm{l}$ : microliter; ppm: parts per million; ${ }^{\circ} \mathrm{C}$ : degrees Celcius.

\section{REFERENCES}

1. Majumder D, Rajesh T, Suting EG, Debbarma A. Detection of seed borne pathogens in wheat: recent trends. Australian Journal of Crop Science. 2013;7(4):500-7.

2. Borgen A. Organic seed treatment to control common bunt (Tilletia tritici) in wheat. Seed Testing International, Issues of Common Technical Interest. 2004;128:8-9.

3. Suzuki EY, Soldati PP, Chaves MGAM, Raposo NRB. Essential Oil from Origanum vulgare Linnaeus: An Alternative against Microorganisms responsible for Bad Perspiration Odour. Journal of Young Pharmacists. 2015;7(1):12-20.

4. Geraldo MRF, Arroteia CC, Kemmelmeier C. The effects of neem [Azadirachta indica A. Juss (Meliaceae)] oil on Fusarium oxysporum f. sp. medicagenis and Fusarium subglutinans and the production of fusaric acid toxin. Advances in Bioscience and Biotechnology. 2010;1(01):1-6.

5. Mbega ER, Mabagala RB, Mortensen CN, Wulff EG. Evaluation of essential oils as seed treatment for the control of Xanthomonas spp. associated with the bacterial leaf spot of tomato in Tanzania. Journal of Plant Pathology. 2012;94(2):273-81.

6. Bhardwaj J, Seth MK, Jameel A, Dinesh C. Antifungal efficacy of essential oils against common bean anthracnose caused by Colletotrichum lindemuthianum. International Journal of Scientific Research and Reviews. 2014;3:22-9.

7. Kavitha KS, Satish S. Bio Prospecting of some medicinal plants explored for antifungal activity. Pharmacognosy Journal. 2016;8(1):59-65.

8. Marinelli E, Orzali L, Lotti E, Riccioni L. Activity of some essential oils against pathogenic seed borne fungi on legumes. Asian Journal of Plant Pathology. 2012;6(3):66-74.

9. Ahmed M, Hossain M, Hassan K, Dash CK. Efficacy of different plant extract on reducing seed borne infection and increasing germination of collected rice seed sample. Universal Journal of Plant Science. 2013;1(3):66-73. 
10. Pathak N, Zaidi RK. Studies on seed-borne fungi of wheat in seed health testing programme. Archives of Phytopathology and Plant Protection. 2013;46(4):389-401

11. Dromph KM, Borgen A. Reduction of viability of soil borne inoculum of common bunt (Tilletia tritici) by collembolans. Soil Biology and Biochemistry. 2001;33(12):1791-5.

12. Singh J, Srivastava S, Sinha SA, Bose B. Studies on seed mycoflora of wheat (Triticum aestivum L.) treated with potassium nitrate and its effect on germination during storage. Research Journal of Seed Science. 2011;4(3):148-56
13. Rajput MA, Pathan MA, Lodhi AM, Shah GS, Khanzada KA. Studies on seed borne fungi of wheat in Sindh province and their effect on seed germination. Pakistan Journal of Botany 2005;37(1):181-5.

14. Hajihasani M, Hajihassani A, Khaghani S. Incidence and distribution of seedborne fungi associated with wheat in Markazi Province, Iran. African Journal of Biotechnology. 2012;11(23):6290-5

15. Zafar M, Jamal A, Tahira R, Zakria M, Naeemullah M. Incidence of seedborne mycoflora in wheat and rice germplasm. International Journal of Agriculture Innovations and Research. 2014;2(5):720-2.

16. Singh S, Goel LB, Sharma SK, Nayar SK. Fungitoxicants and plant extracts in the control of hill bunt of wheat. Indian Phytopathology. 1979;32:297-9.

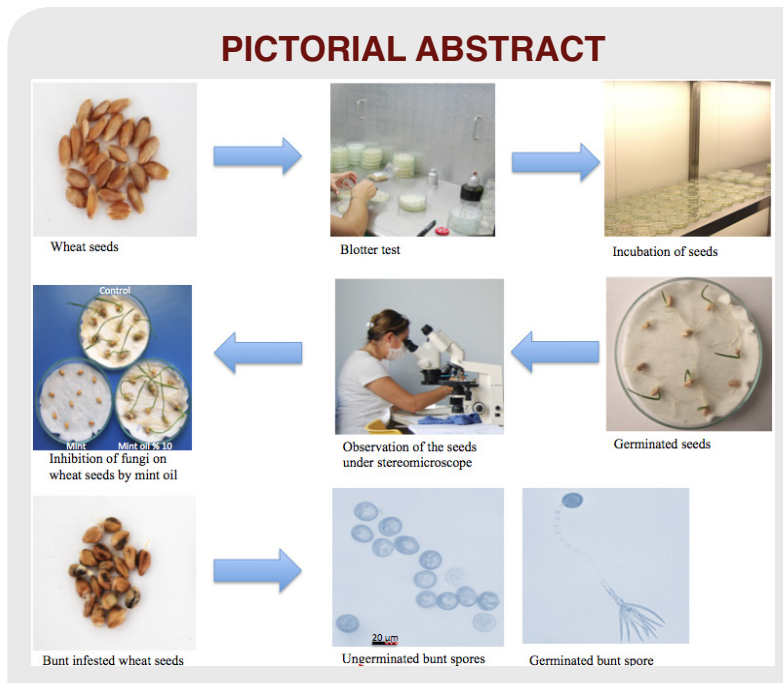

\section{ABOUT AUTHORS}

\section{SUMMARY}

- The objective of the study is to determine the effects of clove, ginger, mint, oregano and thyme essential oils on the fungal load of wheat seeds and on the germination rates of bunt spores. Blotter method was used to determine the effects of different concentrations $(0.05-10 \%)$ of the oils on fungal load of wheat seeds. After incubation at $22^{\circ} \mathrm{C}$ for 7 days, seeds were investigated under stereomicroscope and fungi growing on the seeds were recorded. Germination rates of bunt spores were determined after incubation of spore suspension $(1000$ spores $/ \mathrm{ml})$ on water agar and exposure with different concentrations of oils by two different methods. Highest doses of clove, mint and oregano oils totally inhibited the fungal growth on wheat seeds, but they also inhibited the germination of seeds. Although lower doses failed to inhibit all fungi on seeds, they decreased or totally inhibited the germination of bunt spores.

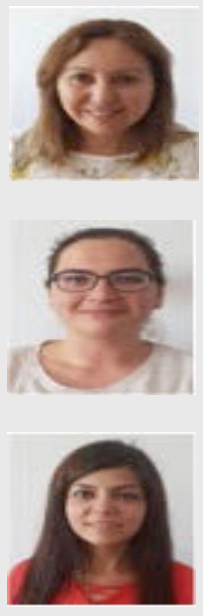

Gürsel Karaca: Is working as a senior lecturer in Department of Plant Protection, Faculty of Agriculture, Süleyman Demirel University, Isparta, Turkey. Areas of interest are seed and soil-borne plant pathogens and biological control.

Melis Bilginturan: Is Ph.D. student and working as a research assistant in Department of Plant Protection, Faculty of Agriculture, Süleyman Demirel University, Isparta, Turkey.

Pinar Olgunsoy: Has M.Sc. degree in Biology and 4th class student in Department of Plant Protection, Faculty of Agriculture, Süleyman Demirel University, Isparta, Turkey.

Cite this article: Karaca G, Bilginturan M, Olgunsoy P. Effects of Some Plant Essential Oils against Fungi on Wheat Seeds. Indian J of Pharmaceutical Education and Research. 2017;51(3)Suppl:S385-88. 